\title{
Professional Development for PreK-12 Teachers in Health Science Content Using a "Train and Equip" Approach: 28 Years' Experience
}

\section{E. Robert Burns, Ph.D.}

Department of Neurobiology and Developmental Sciences, University of Arkansas for Medical Sciences, Little Rock, Arkansas

Keywords: Professional Development, Health Science, PreK-12 Teachers, Workshops

Publication Date: October 21, 2020

DOI: https://doi.org/10.15695/jstem/v3i3.01

\begin{abstract}
From 1991-2019 at the University of Arkansas for Medical Sciences (UAMS), 202 different faculty individuals, from each of the five UAMS colleges, volunteered to offer 120 different workshops in health science content to 22,731 PreK-12 teachers and some school nurses in the Partners in Health Science (PIHS) program. Participants consumed 83,488 hours of professional development. Workshops were held at UAMS or in 39 communities in the state. Workshops provided each participant with a "take home" Resource Kit (RK) containing topic-appropriate materials, supplies and/or items of equipment, used in the workshop, intended to foster replication of workshop experiences in the teacher's home classroom. Short-term, i.e. same day evaluations indicated a high degree of satisfaction with the workshops. Long-term (6 months or longer after a workshop) evaluations revealed that a large number of the participants performed new experiments/ demonstrations and/or classroom activities involving audience participation for their students - a strong sustainability factor because it could last for a participant's entire teaching career. Pre vs. posttest data recorded a gain in knowledge from 1737 participants in several workshops ranging from $14.8 \%$ correct to $29.8 \%$. Extramural funding was consistent, but varied over the duration of the program.
\end{abstract}

\section{INTRODUCTION}

This STEM outreach program, the Partners in Health Sciences (PIHS) program, lasted from 1991-2019 at the University of Arkansas for Medical Sciences (UAMS), the only academic medical center in the state of Arkansas. During that time 202 different faculty individuals in the different UAMS colleges (Medicine, Pharmacy, Nursing, Public Health, Allied Health Professions) volunteered to teach 120 different 1-, 2-, or 3-day (6 hours/day) workshops/mini-courses to 22,731 PreK-12 teachers, and some school nurses, who earned 83,488 hours of professional development (PD) approved by the Arkansas Department of Education and/or the Arkansas Professional Development Registry. PIHS participants attended from all 75 counties in this rural state.

In mid-1990 the concept and goal for the PIHS program originated from the Dean of the College of Medicine "to get UAMS involved in increasing health science education statewide in the PreK-12 arena so that teachers will be better informed and motivated so more of their students would consider careers in the biomedical field". The Dean appointed E. Robert Burns, Ph.D. (ERB), a professor in the Department of Anatomy, to lead this effort. At that point in time ERB was:
1) the course director of a major freshman level anatomy course (Microscopic Anatomy/Medical Embryology) and 2) a funded basic scientist working in experimental oncology, i.e. the use of biological time to improve cancer chemotherapy.

In the 28-year history of the PIHS program providing PD to teachers and some school nurses there were two major components: 1) Phase I targeting grade K-12 teachers and lasting from 1991 to 2004 (to the end of SEPA funding) and 2) Phase II targeting primarily PreK teachers, continuing some K-12 PD, and lasting from 2005 to 2019. Both phases were preceded by pilot projects that were funded by relatively small grants. These pre-phase I and II activities were important because they allowed preliminary data to accumulate that were used to successfully receive major grant funding: 1) a SEPA grant in Phase I and II) a grant from the Division of Child Care and Early Childhood Education (CCECE) of the AR Department of Human Services for Phase II. In Phase I there was a wide variety of health science topics presented by a large number of different UAMS faculty individuals. Only a few Phase I workshops were repeated. Many of the 
participants attended more than one workshop (data unavailable). In Phase II some funding supported K-12 workshops such as "Healthy Skin" by the Arkansas Cancer Coalition, whereas other funding (CCECE) allowed exploration of two topics targeting PreK teachers: "Healthy Hearts" and "Healthy Lungs and Gums". With the success of these PreK pilot efforts, major funding was received from CCECE, and those two topics became the PD offered to PreK teachers statewide. These two topics were chosen for PreK PD because: 1) These organ systems (Cardiovascular and Respiratory) are interconnected in their structure and function and they make noises when they work that children of a young age could hear and, 2) Education in these topics could form an information base for children that could encourage them to think in terms of how to obtain/maintain healthy cardiovascular and respiratory systems. Although these were the only two topics presented and in a 1-day workshop (heart for three hours in the morning and lung for three hours in the afternoon) by one presenter (ERB), they were repeated multiple times in communities throughout the state. Most of the Phase I workshops were held on the UAMS campus with travel reimbursement for participants attending from outside the greater LR/NLR area. In Phase I 96\% of the workshops were 1 -day, 3\% were 2-day, and 1\% were 3 -day. Most of the Phase II workshops were mobile where the only presenter (ERB) traveled to the participants' locations and only one day.

\section{METHODS}

During the fall of 1990 and the spring of 1991 ERB obtained the advice and recommendations of faculty in the Colleges of Education at the University of Arkansas in both Little Rock and Monticello, AR. Other discussions and recommendations were obtained from members of the Arkansas Science Teachers Association, the state's Educational Cooperatives and classroom teachers he worked with in his role as a judge in science fairs. This investigative experience resulted in ERB deciding to structure the PIHS program (Phase I) to 1) cover a wide variety of health science topics, 2 ) include many hands-on activities using supportive materials and 3) obtain the most long-term sustainable effect that would be able to outlast the loss of program funding. The decision was made to use a "train the trainer" approach, and to foster long-term sustainability, i.e. for up to a teacher's entire teaching career, by including a "take home" gift of a resource kit (RK) to each program participant attending any PIHS workshop. The RK would contain topic-specific materials, supplies and/or items of equipment so that a trained teacher would be able annually to offer the new hands-on classroom activities to students. The PIHS program would be open to all teachers in public and private schools, statewide. The goal was to upgrade and expand each participant's knowledge base so that they would be comfortable in teaching the new content to their students and have matching RKs in support of this. Consequently, the PIHS program became a "train and equip" activity.

The contents of the RK given to every PIHS participant varied with the health science content covered in a workshop. For example, in the workshop covering the basic anatomy and physiology of the cardiovascular system the RK contained plastic models of the heart and the development of atherosclerosis in arteries, a medical student grade stethoscope, microscope slides of the layers of the heart and its valves and different types of blood vessels, a blood pressure cuff, a dissected and un-dissected pig, sheep, or cow heart, and each participants' personal ECG recording. The RK for participants exiting the Cell Biology, Muscular Dystrophy, or Sickle Cell Anemia workshops received, in addition to microscope slides, etc. a gel electrophoresis chamber and power supply and all reagents to replicate workshop laboratory exercises in their home classroom. When a teacher using this laboratory-based experience with her/his students exhausted the RK consumable reagents, the school was expected to replenish these (no data available).

In addition to the topic-specific items in the RKs, every kit included a profusely illustrated syllabus authored by PIHS faculty members teaching the workshop and a CD of all images used in the training. Also, most PIHS workshops contained many audience-participation activities specifically designed for replication by students in their home classroom. Such activities were organ specific and, therefore, varied significantly. For example, in workshops dealing with the cardiovascular system the teachers learned and participated in the "blood walk" activity (Burns, 2008a); in the "Healthy Lungs" workshop the teachers learned how to perform the "ciliary wave" and how cigarette smoke alters its normal function resulting in the functional anatomy of the smoker's respiratory system (Burns, 2012); in the "Healthy Skin" workshop the audience participated in making the different layers of the epidermis using paper plates representing the cells in the different layers (Burns, 2017).

Shortly after the beginning of the PIHS program several workshops targeted the central nervous system and those participants were given, in addition to the topic-specific RK items, a Jell-O mold of a human half-brain and a two-page handout identifying the different functional areas of the cortex, i.e. motor, sensory, visual, etc. This addition to the nervous system RKs became so popular (word of mouth advertising) that from that point on the Jell-O brain mold and supporting document were a component of every RK in the SEPA funded part of Phase I, regardless of the topic presented in the workshop. Each workshop provided the participants with an on-site lunch with funding usually from local community organizations.

All UAMS faculty presenters were coached by ERB to 
consider the participants as "colleagues in education" and respect them for the job they do, many times under less than ideal circumstances. Indeed, the motto of the PIHS program became "Teachers Teaching Teachers" underlined with arrowheads pointing in both directions indicating that UAMS faculty presenters learned about teaching from these professionally trained educators with expertise in "educational best practices" as they were learning new health science information.

The typical workshop began with a welcome that included acknowledgement of the PIHS motto that could also be stated as "Colleagues Teaching Colleagues". The typical workshop involved the presentation of the relevant basic science content, usually including a hands-on laboratory experience and ended with a clinical presentation. For example, in the "Sickle Cell Anemia" workshop an anatomist presented the structure of all of the formed elements of blood. This included study of both light and electron microscopic images of and the different functions of each of the formed elements, such as the platelet role in clot formation, role of each of the white blood cells in immune function, etc. Special attention was given to the light, transmission and scanning electron microscopic images of normal and abnormal red blood cells. Then a biochemist presented an overview of the hemoglobinopathies with emphasis on hemoglobin $\mathrm{S}(\mathrm{HbS})$. The teachers then went to a teaching laboratory where they studied their RK microscope slides of normal and sickle cell anemia. Then each of them set up their own gel electrophoresis experiment using $\mathrm{HbA}, \mathrm{HbS}$ and $\mathrm{HbC}$ lanes. After the lunch break the biochemist led the group through a discussion of the results of the electrophoresis experiment. The class then experienced a presentation by a pediatrician involved in diagnosing and treating sickle cell anemia. The teachers exited the workshop with microscope slides of normal and sickle cell blood, a power supply and electrophoresis chamber, and all of the reagents needed to replicate the experiment in their home classroom.

There was plenty of time for questions and answers and feedback during the workshop day, i.e. during the frequent breaks in the morning and afternoon sessions, over the lunch period, and at the very end of a workshop when a "open discussion" session was held. Sometimes teachers in the same grade levels would informally group together to exchange ideas about how they were thinking about designing classroom activities in addition to replicating workshop activities, but this was not a formal component of the workshops. We noticed that there seemed to be more of that kind of exchange going on in the Phase II workshops that targeted only PreK teachers. Even after that session ended, many of the participants stayed for more discussion. All faculty teaching a workshop agreed to "stay until the last participant left".

The first workshop occurred in the summer of 1991 with 13 teachers from the Little Rock and North Little Rock school districts. The topic was "Medical Embryology" and taught by ERB. Each participant received a copy (paid for by the Dean of the College of Medicine) of a medical embryology textbook. From that beginning, the PIHS experience has involved thousands of participants and produced several publications (Kirchner et al., 2000; Burns, 2002; Burns and Lindsey, 2004; Burns, 2008a; 2008b; 2012; 2014; 2017). Detailed data on program evaluation and events exist in these publications that also include review of publications by others. For this paper, some of the evaluation data have been extracted from these publications and presented in condensed/summary form. All PIHS evaluations were conducted by Ph.D./Ed.D. level faculty and their staff in the UAMS Office of Educational Development, which provides a variety of support to teaching faculty in all colleges at UAMS.

To recruit participants announcements and registration forms for upcoming PIHS workshops were mailed using merged mailing lists from individual school districts in the state, membership of the Arkansas Science Teachers Association, Head Start, Arkansas Better Chance, Educational Coops, Math and Science Centers, all alumni of the program, etc. As the program evolved, online registration became available from the Arkansas Professional Development Registry. Although for Phase I the target audience was the grade 7-12 teacher of biology/science/health, registrations were received from school nurses, teachers from elementary grade levels, some school administrators, etc. We accepted everyone. This is how school nurses became involved. "Others" were people like the administrator who had just had coronary by-pass surgery and wanted to get self-educated in the general topic of heart health. Another example of a non-targeted participant was the HS mathematics teacher who attended the "Healthy Skin" workshop, because her daughter had been diagnosed with malignant melanoma.

In Phase I about 14,000 brochures were mailed out. In Phase II about 1000 flyers were mailed out announcing each community-based workshop. Note that the participants volunteered to attend a workshop(s). Therefore, most of them were motivated by a desire to learn new health science information. Their high level of motivation was frequently praised by UAMS faculty presenters. One way to summarize this is to record a common participant answer to an open-ended question on the workshop evaluation form: "What was the worst thing about the workshop"? Answers were "nothing", "it was too short", etc.

The contents of the topic-specific RKs, other than the faculty generated workshop syllabi and CDs of all lecture images, were purchased with extramural grant funds using the contracts UAMS and its clinics/hospitals negotiated with different commercial suppliers. This resulted in significant discounts for purchased items, e.g. a RK containing about $\$ 500$ worth of items at street price cost PIHS about $\$ 300$. 
Table 1. Data collected for participants in Phase I and Phase II of the PIHS program.

\begin{tabular}{lcc}
\hline Item & Phase 1 & Phase II \\
\hline Workshop Location & On UAMS Campus & Off UAMS Campus \\
Female Participants & $69 \%$ & $31 \%$ \\
Male Participants & $85 \%$ & $90 \%$ \\
Teacher Participants & $15 \%$ & $10 \%$ \\
Nurse Participants & $71 \%$ & $85 \%$ \\
Other Participants & $21 \%$ & $7 \%$ \\
No Data from Participants & $4 \%$ & $8 \%$ \\
Urban Based Participants & $4 \%$ & $0 \%$ \\
Rural Based Participants & $52 \%$ & $35 \%$ \\
Caucasian & $48 \%$ & $65 \%$ \\
African American & $80 \%$ & $74 \%$ \\
Other Races & $14 \%$ & $22 \%$ \\
\hline
\end{tabular}

\section{RESULTS}

Information regarding program participants for both Phases of the program appear in Table 1. All participants attended the same workshop, i.e. there were no segments in a workshop targeting teachers vs. nurses, high school teachers vs. middle school teachers vs. elementary school teachers. It was recommended that each of them extract workshop information and activities they thought would be appropriate for the student grade level they taught. During the early years of Phase II the Arkansas Cancer Coalition funded a workshop on "Healthy Skin" targeting grade K-12 teachers and CCECE funded pilot projects to see if health science PD, such as healthy hearts and lungs would be applicable PD for PreK teachers and their students. This information is included in Phase II data. The breakdown is as follows: 61\% of Participants in Phase II were PreK and 39\% were K-12. For the entire 28 years of the PIHS program there were $78 \%$ teachers, $18 \%$ nurses and $4 \%$ others. In Phase I $83 \%$ of the teacher-participants taught grade levels 7-12 and $17 \%$ taught grade levels 5-6. We have no data on what disciplines the grade 7-12 teachers taught. Informal interactions with them revealed that most of them taught science, biology, and/or health classes. Workshops held at UAMS targeted grade 7-12 teachers targeted one health science topic and usually involved a laboratory session. Workshops targeting PreK teachers were not as intense and presented two topics in one day (Heart and Lungs). No workshop participant received any compensation for attending, except for the receipt of PD credit.

The average attendance at a workshop was about 35, but ranged from a low of 13 for the very first workshop up to 162 for the workshop on ADHD. The highest participation rate was always associated with topics in behavioral science such as: "Adolescent Medicine". "Kids and Drugs", "Stress Management", "Depression", etc. No workshop participant received any financial incentive to attend.

Some data selected and reformatted from previous PIHS publications are included. Table 2 is a summary of a satisfaction survey (1991-1995); data from 10/19 original survey questions ( $\mathrm{N}=302$; from Burns, 2002). Similar results have been recorded for every workshop. Overall there was a high degree of participant satisfaction with PIHS workshops.

At the end of the tenth year of the program (1991-2001) a questionnaire was mailed to 1,052 alumni of the program who had returned home after exiting a workshop for a minimum of six months. There were 300 returns. This tool was designed to capture data on the long-term effects of the program. The data appear in Table 3 (from Burns, 2002).

Regarding the last statement, note that because school nurses also attended PIHS workshops but would not be expected to offer new laboratory experiences for students, the responses to this question were entered into an Excel spreadsheet and subjected to analysis by using SPSS (Statistical Program for the Social Sciences, version 10.1 software for Windows). For comparison, variables were grouped into areas of specific interest and then analyzed at a descriptive statistical level. All incomplete surveys were included in the analyses; therefore, the percentage data do not always to-

Table 2. Satisfaction Survey of Program Participants. Likert scale, $5=$ strongly agree.

\begin{tabular}{|c|c|}
\hline My PIHS experience was professionally beneficial to me as a teacher & $4.70+/-0.05$ \\
\hline My PIHS experience was beneficial, through me, for my students & $4.56+/-0.06$ \\
\hline I learned some new information in the health science topic(s) I attended & $4.78+/-0.04$ \\
\hline $\begin{array}{l}\text { The syllabus and/or other handouts or booklets or links to websites or video tapes provided by the workshop faculty were helpful/ } \\
\text { useful }\end{array}$ & $4.52+/-0.06$ \\
\hline The PIHS course(s) I attended had a positive motivational impact on me & $4.61+/-0.06$ \\
\hline I repackaged at least some of the material I learned in the program and presented it to my students & $4.25+/-0.08$ \\
\hline I have done some new demonstrations and/or laboratory type exercises for my students as a direct result of my PIHS experience & $3.89+/-0.09$ \\
\hline $\begin{array}{l}\text { When I leave each PIHS course I have taken I would like to leave with even more take home supplies, materials and items of } \\
\text { equipment }\end{array}$ & $4.47+/-0.08$ \\
\hline The material given to me in the PIHS program was useful for my students & $4.42+/-0.07$ \\
\hline In general, my experience in the PIHS program was one of the most beneficial/useful events in my professional development & $4.48+/-0.07$ \\
\hline
\end{tabular}


Table 3. Results from 300/1,052 respondents, 1991-2001, regarding a long-term evaluation (\%Yes vs. \%No).

\begin{tabular}{|c|c|c|}
\hline Response & Yes $(\%)$ & No $(\%)$ \\
\hline Have you participated in more than one PIHS workshop prior to $2001 ?$ & 77 & 23 \\
\hline In regard to your professional development was your PIHS training a positive experience for you? & 99 & 0 \\
\hline In your opinion was this training experience valuable, through you, for any (one or more) of your colleagues? & 97 & 2 \\
\hline Was this training experience valuable, through you, for your students? & 94 & 1 \\
\hline Did you share some of the information you learned in the workshop(s) with your colleagues? & 93 & 3 \\
\hline Did you share some of the information you learned in the workshop(s) with your students? & 83 & 5 \\
\hline $\begin{array}{l}\text { Did you use any of the supplies or materials such as color laminated photos, videotapes, preserved organs, reprints, texts, } \\
\text { charts, etc. with your students/patients? }\end{array}$ & 76 & 10 \\
\hline Did you perform any new laboratory-type exercises or demonstrations with your students as a result of your PIHS training? & 36 & 46 \\
\hline
\end{tabular}

tal to $100 \%$. No inferential statistics were performed, as the main focus of analysis was limited to a descriptive review of the survey data. This strategy allowed the data obtained to be examined in a variety of ways. Of the respondents to the last question in the survey, only $36 \%$ reported that they performed new laboratory-type exercises/demonstrations with their students and 46\% answered "no"; however, 48\% of the overall respondents were nurses and might be expected to say "no" to this question. By using SPSS to select out the responses of only the teachers and compare this with non-teacher respondents, it was discovered that $54 \%$ of the teachers reported that they performed new laboratory-type classroom experiments or demonstrations with/for their students as a direct result of their participation in the PIHS program. Interestingly, $17 \%$ of the non-teacher respondents stated that they too performed a new demonstration with their "patients", which are students. Seventy-six percent of all respondents stated that they used the supplies/materials/ equipment provided in the RKs with their students. As expected, participants who previously attended the program before 2001, i.e., were not attending the program for the first time, accounted for more PIHS-based, classroom activities than the first-time participants: $97.0 \%$ vs. $84.3 \%$; for "valuable experience for students"; $86.5 \%$ vs. $82.9 \%$ for "share with colleagues"; $87.5 \%$ vs. $44.3 \%$ for "use supplies"; and $40.9 \%$ vs. $18.6 \%$ for "lab/demo with students". The largest discrepancy between the new and prior program alumni was for conducting a laboratory experiment or demonstration. This finding was expected, because the survey was performed only a few months after the completion of the summer PIHS program and most of the participants probably did not have enough time to design and offer a new lab exercise or demonstration for their students. The data indicate that with time, the first-time attendees will increase the number of laboratory experiences and/or demonstrations they perform for/with their students. No differences were found between rural vs. urban-based participants for all categories, e.g. $93.6 \%$ vs. $94.9 \%$ for "share with colleagues"; $85.5 \%$ vs. $85.3 \%$ for "share with students", etc.

Another long-term evaluation (Table 4; adapted from
Burns, 2012) was conducted with teacher-participants after the "Healthy Lungs" workshops (data collected from 2006-2010). The implementation survey was mailed only to teacher-alumni of the workshop who had a minimum of six months after the training event to return to their classroom and implement or not implement some of the newly learned content and/or use of the RK items and/or use of the handson, audience participation activities. The response rate was $54 \%(348 / 645)$.

Consistent with the results of the long-term survey conducted from 1991-2001 a large number of the teachers transferred the new information about lung health to their students and also performed new classroom activities with/for their students. Two other long-term surveys (for a total of 4 for the program) were conducted with similar positive results: "Healthy Hearts" (Burns, 2008b) and "Healthy Skin" (Burns, 2017).

Regarding pre/posttest knowledge acquisition/gain, for most of the workshops (not the very early ones) participants completed a pretest before a workshop began and a posttest at completion of the workshop. For example, for the "Healthy Hearts" workshops $(\mathrm{N}=642)$ the overall gain in new knowledge was $+14.8 \%$ correct (Burns, 2008). For the "Healthy Lungs" workshop $(\mathrm{N}=576)$ the overall gain was $29.8 \%$ (Burns, 2012) and for the "Healthy Skin" workshop $(\mathrm{N}=519)$ the overall gain was $28.5 \%$ (Burns, 2017).

All evaluation tools contained an open-ended section for written comments. Some comments were: "We electrophoresed DNA at our school for the first time"; "I have always been uncomfortable in my knowledge of the func-

Table 4. Long-Term Survey of Teacher-Participants in the "Healthy Lungs" Workshops. \% strongly agree +\% agree = total \% agreeing.

\begin{tabular}{ll}
\hline The materials received were useful as teaching aids. & 97.8 \\
This training gave me skills to use with my class. & 95.6 \\
The information was transferable to child learning. & 88.0 \\
I transformed PIHS activities into classroom learning. & 87.9 \\
These activities held the children's interest. & 81.4 \\
These activities were appropriate for my students. & 83.5 \\
The children gained knowledge from this unit. & 89.0 \\
\hline
\end{tabular}


tional anatomy of the heart and, therefore, did not teach it or dissect slaughter house hearts with my students like other teachers I know did - but now after taking the PIHS course in the anatomy and physiology of the cardiovascular system, I will have my students learn detailed information about the heart and they will dissect hearts from now on."

\section{DISCUSSION}

The PIHS program with a statewide reach was successful in many categories: 1) In both short and long-term evaluation measures; 2) The popularity of the program as exhibited by the large number of participants from every county in the state; 3) The large number of hours of professional development earned by the program participants and 4) The 28 consecutive years of program history.

To maximize and broaden the overall educational effect of this outreach, a wide variety of different health science topics were taught by many different UAMS faculty members volunteering to do so. The program included 2 major components: 1) Train teachers using a workshop format with face-to-face interaction between presenters and participants and 2) Possibly a unique feature of also providing each workshop participant with the gift of a RK containing permanent, topic-specific supplies, materials and/or items of equipment used in the workshop training and specifically designed for replication of hands-on workshop activities in the participants' community classrooms. This combination of "train and equip" motivated a large number of program alumni to offer new health science curricular activities in their home classrooms and share the new information and RK items with colleagues. Because of the permanent nature of the items in a topic-specific RK, the transference of that new information and use of the RK items to students happened relatively quickly, i.e. without any delay to wait for an opportunity to field-trip to a brick and mortar research laboratory or have a mobile teaching lab visit their school. Additionally, because of the gift of a RK/each health science topic, the "train and equip" approach has the potential to last a program participant's entire teaching career, thereby impacting thousands of students.

Administrative Support and Volunteer Teaching Faculty. Administrative support from the highest level was crucial to maintaining the program for 28 years. This resides in the fact that the original idea for the outreach effort came from the Dean of Medicine, who later became UAMS Chancellor (Dodd Wilson, M.D.). This administrative support kept the program intact even when extramural funding was at low levels. For example, it included access to available lecture rooms, wet and dry teaching labs, computer labs, teaching lab support personnel, campus media services, etc. Additionally, when relatively small extramural funding arrived, central administration agreed to let the program director spend the funds on program activities and forgo director's salary and indirect costs recovery. When larger extramural funding was obtained, some indirect costs were captured (8$11 \%$ ) and salary recovery occurred only for the program director and a part-time administrative assistant. All involved UAMS faculty and their staff donated their time.

In the early startup years of the program the author used his 23 years of collaborative service and interactions as a faculty member teaching medical and graduate students, a course director and/or teacher for both medical and graduate school courses, a basic science researcher and service on several COM and campus-wide committees (chair, animal care committee; chair committee on committees, radiation safety committee, UAMS Faculty/Student Appeals Board, etc. This involvement permitted ERB to recruit faculty individuals, many of them parents and grandparents, known to be excellent teachers, to volunteer to teach in the PIHS program. In just a few years, however, these "favors to volunteer" began to decrease to a perceived dangerous level. ERB then met with the COM Dean and informed him of this threat to the success of the program. At a subsequent COM faculty meeting the Dean addressed this topic and encouraged members of the COM faculty to help. There was a noticeable increase in faculty volunteering to work in the program. When Dr. Wilson became UAMS Chancellor as well as his successors as Deans or Chancellors, this "pressure" to volunteer remained for the duration of Phase I with ERB becoming the only workshop instructor in Phase II. ERB also informed two presidents of the University of Arkansas system about the PIHS program and they were pleased with its statewide success, probably from a PR/political stance.

Financial Support. The total extramural funding for both Phase I and II was $\$ 3,713,716$. Extramural support was received from the following organizations listed in alphabetical order: American Physiological Society, Arkansas Cancer Coalition, Arkansas Department of Health, Arkansas Department of Human Services, Division of Childcare and Early Childhood Education, Arkansas Department of Higher Education (Eisenhower Mathematics and Science Award), Arkansas Head Start - State Collaboration Project, Arkansas Prostate Cancer Foundation, Bank of America, BankCorp South, Jennings Osborne (philanthropist), Kellogg Foundation, Merck Company, National Center for Research Resources - Nation Institutes of Health Science Education Partnership Award (phase I), National Science Foundation, and the Pfizer Company. These funding levels could be categorized as high (about \$200,000/year with SEPA), medium (about $\$ 100,000 /$ year with CCECE funding) and low ( $\$ 300$ to $\$ 50,000$ / year such as grants from the Arkansas Cancer Coalition, AR Prostate Cancer Foundation, AR Department of Health, AR Department of Higher Education, Kellogg 
Foundation, and some community banks). The program was consistently seeking any source of extramural funding in both the pre-Phase I and pre-Phase II arenas to get the program started and to keep it going until major funding arrived. Regarding CCECE funding, it reached a major level after its lesser funding supported pilot studies to determine if Heart and Lung health science content could be made grade-appropriate for 4-5-year-old children and their teachers (manuscript in preparation). In Phase I, with excellent support from SEPA, each workshop/ mini-course director received \$3000/workshop day to be spent on workshop and RK materials only. None of these dollars were used for salary recovery for volunteering faculty individuals.

Use of Evaluation Feedback. The formal and informal evaluations by the participants were very helpful in improving the design and activities of the program and its workshops. Regarding the program design, teacher input was incorporated so that all workshops occurred on Tuesdays-Wednesday-Thursdays and from the middle of June to early August. There were many teaching suggestions made by the professional educators attending workshops. Many of these were written comments in the open-ended section of each evaluation document. Comments/suggestions also were received by e-mail. Some of these were aimed at improving workshop experience such as "more hands-on activities", "more frequent breaks", "laminate the $8 \times 10$ color prints in the RK for student use", "for the students to experience an asthma attack give each of them a soda straw to breathe through, then have them progressively pinch the straw making it more and more difficult to breath", etc. These suggestions were incorporated into the working of the program and/or its workshops. There were other suggestions that targeted home classroom activities, not program workshop activities. An example that was included in every "Healthy Heart" workshop as a teacher-suggested activity was received by e-mail: "I got large cardboard boxes from to make the 4 chambers of the heart and the two lungs. I had my students crawl through, in the correct sequence as blood moved using blue streamers for deoxygenated blood and red streamers for oxygenated blood and white streamers for air flow". Other such recommendations as to what participants did on their own initiative are available in PIHS publications in the reference section.

When the target of this PD effort in Phase II became the PreK teacher (those dealing with 4- and 5-year-old children), the pilot workshop topic was "Healthy Hearts". In the development of that workshop the teachers advised us to set aside some "lab" time" where they broke into groups to discuss and design hands-on activities for their students using the newly learned health science content. One group produced some sing-along songs; another group developed construc- tion paper models of the heart and great vessels using the colors blue and red; another group developed a task in which the students built a heart with great vessels using red and blue clay. These activities consumed about $70 \%$ of the workshop time of six hours, but were incorporated into several pilot workshops. However, when the funding agency for the PreK part of Phase II asked for the program also to include the functional anatomy of the lung with segments on asthma and oral health, the "Healthy Hearts" and "Healthy Lungs and Gums" one-day workshop came into existence resulting in both topics being covered in one 6-hour workshop. To provide the PreK teachers with a "lab" experience, every PreK workshop had a "lab" component where the teachers could hold and study plastinated normal and abnormal human specimens (e.g. atherosclerosis, aneurysms, pneumonia, lung cancer, etc.). Images of all of these situations were included in the RK-CD along with suggested activities for student involvement in songs, clay models, etc.

The on-campus activities of the PIHS program in Phase I created an interest in many faculty members not only to volunteer to teach in the program, but for some of them to pursue funding for educational outreach in their arena of expertise. Faculty members in the Departments of Psychiatry, and Family and Community Medicine volunteered to offer some PIHS courses such as "Stress Management", "ADHD", etc. This experience provided them with enough data for a publication (Kirchner et al. 2000), which also served as supporting data for the application and eventual receipt of a 5-year SEPA grant entitled "Partners in Behavioral Health Sciences" (PIBHS), that continued to use the original PIHS concept of "train and equip" teachers. Recently some UAMS faculty, well aware of the PIHS and PIBHS SEPA funded programs, received a SEPA grant to work directly with high school students in the Little Rock school district. The focus was on the physics and medical uses of sonography (ArkanSONO). Because the original PIHS program captured SEPA funding in two competitive applications and PIBHS and ArkanSONO) also were successful SEPA grants, the UAMS College of Medicine has held four SEPA grants.

The gift of a topic-specific RK to each participant was very popular and is believed to be a significant factor in the overall success of the program because not only do they have the training and new information, but they also have a set of permanent "tools" to help them teach the content in the same way they learned to do that during a PIHS workshop.

The "train and equip" method of providing PD to classroom teachers is not restricted to health science. This method could be used to provide PD in any STEM discipline and even to those in the PreK arena. 


\section{AUTHOR INFORMATION}

\section{Corresponding Author}

E. Robert Burns, Ph.D. Professor Emeritus, Department of Neurobiology and Developmental Sciences, College of Medicine, University of Arkansas for Medical Sciences. 4301 W. Markham St. Little Rock, AR 72205. burnsbob@ uams.edu

\section{ABBREVIATIONS}

CCECE: Division of Child Care and Early Childhood Education; COM: College of Medicine; ERB: E. Robert Burns, Ph.D.; PD: HbS: Hemoglobin S; Professional Development; PIHS: Partners in Health Science; RK: Resource Kit; SPSS: Statistical Program for the Social Sciences; UAMS: University of Arkansas for Medical Sciences;

\section{REFERENCES}

Burns, E. R. (2002). Anatomy of a successful K-12 educational outreach program in the health sciences-eleven years' experience at one medical sciences campus. Anatomical Record (New Anatomist), 269, 181-193.

Burns, E. R., and Lindsey M.S. (2004), Cancer education and cancer prevention education for K-12 teachers and students. Journal of Cancer Education, 19, 105-110.

Burns, E. R. (2008a). Use of the published Lance Armstrong cancer story to teach health science content to high school students. The American Biology Teacher, 70, 17-22.

Burns, E. R. (2008b). Functional anatomy of the cardiovascular system: Professional development for preK-3 teachers using a "Train and Equip" method results in learning opportunities for students. Journal of Anatomical Science Education, 1, 119-125.

Burns, E. R. (2012). Healthy lungs: Cancer education for middle school teachers using a "Train and Equip" method. Journal of Cancer Education, 27(1), 179-185.

Burns, E. R. (2014). Cancer prevention and control: Where are the kids? Journal of Cancer Education, 29 (2), 209-210.

Burns, E.R. (2017). Healthy skin: Cancer education for school teachers and nurses using a "Train and Equip" method. Journal of Cancer Education, 32, 72-78.

Kirchner, J.E, Yoder, M.C, Kramer, T.L, Lindsey, M.S., and Thrush, C.R. (2000). Development of an educational program to increase school personnel's awareness about child and adolescent depression. Education, 121, 235-246. 